\title{
Eye-Blink Rates and Depression Is the Antidepressant Effect of Sleep Deprivation Mediated by the Dopamine System?
}

\author{
Dieter Ebert, M.D., Roland Albert, M.D., Gerhard Hammon, Bernhard Strasser,
} Albrecht May, M.D., and Antje Merz, M.D.

A series of studies demonstrated a possible correlation between eye-blink rate and central dopamine activity. The hypothesis has been put forward that the antidepressant effect of sleep deprivation (SD) is mediated by an enhanced dopamine release resulting in an amphetaminelike action of $S D$. Therefore, the blink rates of 12 drug-naive patients with major depression and 12 healthly controls were compared before and after $S D$ and before and after $2.5 \mathrm{mg}$ bromocriptine as a dopaminergic challenge. The main result of the study was that the depressed patients had a signficantly higher increase of blinking after SD both with and without a dopaminergic challenge. Basal eye-blink rate was not different in nonretarded major depression patients compared to controls. Sleep deprivation increased blink rate in depression patients but not in controls, and the increase was proportional to improvements in depressive state after sleep deprivation. Bromocriptine did not increase blink rate 1 hour after application. This result is consistent with the hypothesis that antidepressant SD acts through dopamine release, although it is not conclusive, because other neurotransmitters like acetylcholine may be involved in the regulation of blinking. [Neuropsychopharmacology 15:332-339, 1996]
KEY WORDS: Eye-Blink rate; Dopamine; Sleep deprivation; Bromocriptine; Depression

A series of studies demonstrated a possible correlation between eye-blink rate and central dopamine activity (Hall 1945; Stevens 1978; Casey et al. 1980; Karson et al. 1981a,b; Karson 1983; Lawrence and Redmond 1991). The blink-rate is reduced in Parkinson's disease (Hall 1945). Dopamine agonists, like apomorphine and bromocriptine, increase blink rates in monkeys, an effect that can be blocked by pretreatment with dopamine antagonists or by destroying dopaminergic pathways (Casey et al. 1980; Karson et al. 1981a; Karson 1983;

From the Department of Psychiatry, University of Erlangen, Germany.

Address correspondence to: Dieter Ebert, M.D., Department of Psychiatry, University of Erlangen, Schwabachanlage 6, 91054 Erlangen, Germany.

Received July 26, 1995; revised October 24, 1995; accepted October 25, 1995.
Lawrence and Redmond 1991). Neuroleptic treatment reduces blink rates (Karson et al. 1981b; Karson 1983). From these studies, it can be concluded that spontaneous blink rates correlate positively with the activity of midbrain dopamine systems. However, the exact anatomy of spontaneous blinking in humans is not known, and the central nervous center that controls the rate of spontaneous blinking is obscure, although it probably is located in the areas of the brainstem reticular formation (Doane 1994; Records 1993). In addition, undefined areas of the basal ganglia regulate blinking (Doane 1994; Records 1993). In animal studies, lesions of the dopaminergic pathways of the substantia nigra retard eyeblink conditioning (Kao and Powell 1988). The eyelid of the rat receives abundant dopaminergic sympathetic innervation, as well as moderate parasympathetic and sensory calcitonin gene-related peptid projections from trigeminal neurons and the superior cervical ganglia, which is consistent with the idea that eye-blinks are also 


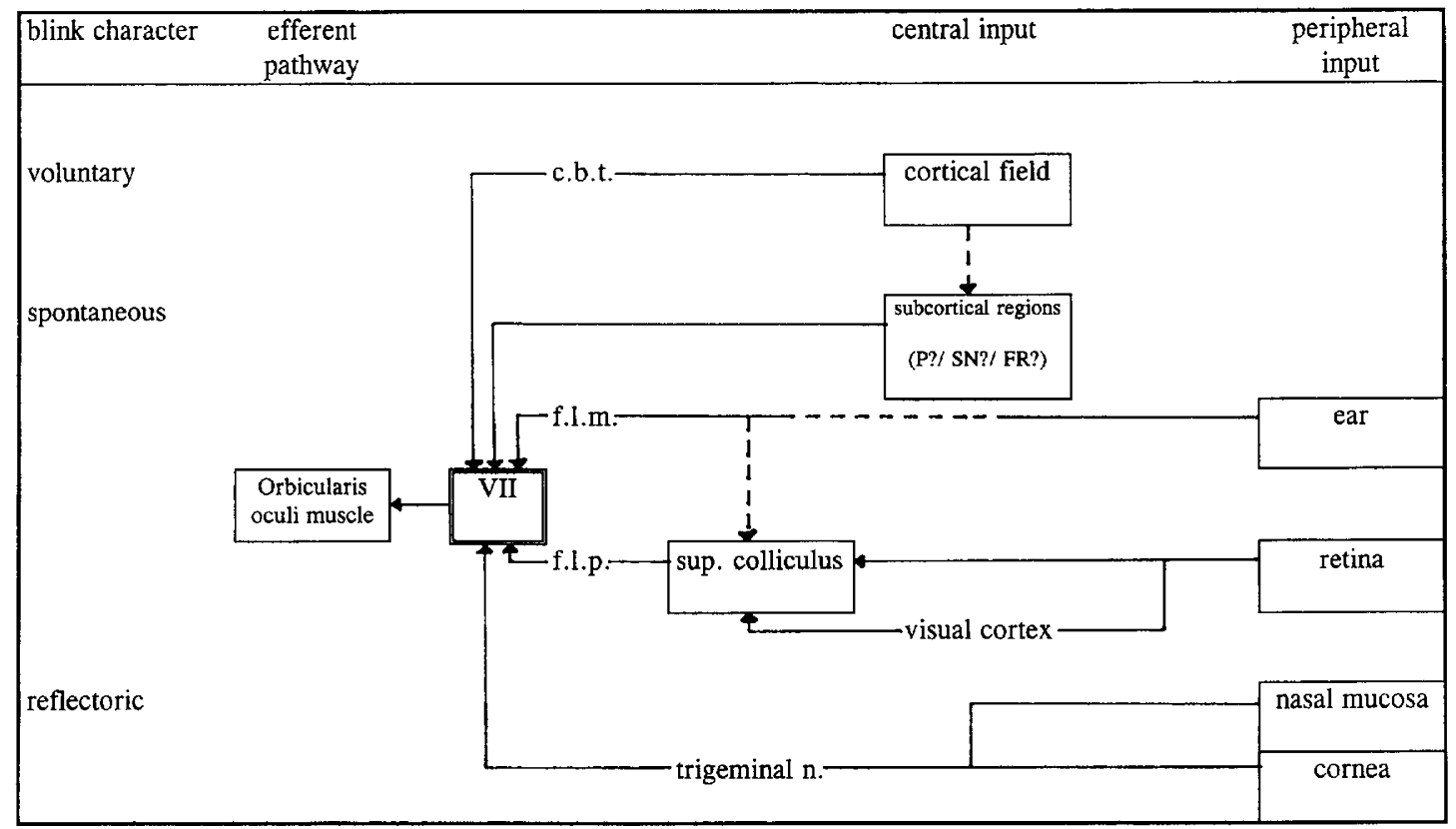

Figure 1. Diagram illustrating various anatomic structures involved in different lid-closure mechanisms (contractile part of blinking). c.b.t. $=$ corticobulbar tract; f.1.m. $=$ fasciculus longitudinalis medialis; f.l.p. $=$ fasciculus longitudinalis posterioris; $\mathrm{P}=$ pallidum; $\mathrm{SN}=$ substantia nigra; $\mathrm{FR}=$ formatio reticularis; $\mathrm{n} .=$ nerve; $\mathrm{VII}=$ nucleus originis of facial nerve

regulated by peripheral innervation (Simons and Smith 1994). In an update of all anatomic regions influencing blinking, Karson et al. (1990) concluded that the neuroregulation of blink rate involves a complex neurocircuit of which the midbrain dopamine systems are but components. Blinks are generated in the reticular formation of the rostral pons and regulated by the substantia nigra, superior colliculus, the occipital cortex via the lateral geniculate body, and optic radiations. Furthermore, thalamic structures, neurocircuits involving memorization and inhibiting influences of the cerebellum, have been involved in the physiology of blinking (Figure 1).

Blink rates often have been studied in schizophrenia (for a review, see Karson et al. 1990)-with the most common result being an increased blink rate. Studies dealing with blinking in affective disorders are rare, although recent evidence suggests that mesolimbic dopamine-containing neurons may be involved in the pathophysiology of some types of depression and may be a substrate for the therapeutic actions of some antidepressant drugs (for recent reviews, see Fibiger 1995; Willner 1994). Up to now, both increased and decreased blink rates have been reported in depression (Ostow and Ostow 1945; Mackintosh et al. 1983). Depue et al. (1990) observed that patients with seasonal affective disorder had an increased blink rate compared to controls, a trait marker of seasonal affective disorder.

Recently, we proposed that the antidepressant effect of sleep deprivation (SD) is mediated by an enhanced dopamine release resulting in an amphetaminelike ac- tion of SD. In both single photon \& emission tomography (SPECT) and positron emission tomography (PET) SD has suppressed limbic hypermetabolism in SD responders (Ebert et al. 1991, 1994a; Wu et al. 1992, 1994), and the hypermetabolic structures are part of limbic circuits rich with dopaminergic pathways and postulated to play a key role in depression (Ebert and Ebmeier 1995, Pearlson and Schlaepfer 1995). Sleep deprivation responders showed a higher striatal dopamine release after SD than nonresponders measured with 123-iodobenzamide IBZM-SPECT (Ebert et al. 1994b). After SD, the prolactin response to the $D_{2}$ receptor antagonist sulpiride was greater in responders than in nonresponders possibly due to changed receptor sensitivities as a consequence of increased dopamine release in responders (Ebert et al. 1993). An increase in catecholamine metabolites during SD is one of the most consistent findings in SD responders (for a review, see Ebert and Kaschka 1995). Recently, it was shown that SD induces changes in light sensitivity proportional to improvements in depressive state, and light responses depend upon CAMP and dopamine (Sokolski et al. 1995). The direction of change can be explained best by an increase in dopamine release or a (consecutive) decrease in dopamine receptor sensitivity in SD responders. Data from animal studies indicate that the behavioral syndrome induced by SD (hyperactivity, irritability, aggressiveness, hypersexuality, stereotypy, decreased need of sleep) is critically dependent on dopaminergic activity, $D_{1}$ and $D_{2}$ dopamine receptors interact, and $D_{1}$ receptor 
activation seems to be essential for the expression of $D_{2}$ receptor stimulation. Relevant changes have been observed in mesolimbic $\mathrm{D}_{1}$ and opioid receptors, but not in striatal receptors or in adrenergic or serotonergic receptors (for a recent review, see Gessa et al. 1995). However, the interpretation of animal studies is difficult, considering the absence of an animal model of depression and the differences between patients and controls in clinical response to SD. Several studies have investigated cognitive functions, alertness, and sleepiness in sleep-deprived normal volunteers with and without catecholamine depletion (McCann et al. 1992, 1993, 1995), with the result that SD is associated with a decrease in catecholamine functions. This is not a contradiction to the aforementioned results, but it gives further evidence that controls, depressed nonresponders, and depressed responders react differently upon SD. Furthermore, the downregulation of catecholamine neurotransmission involved in cognitive functions may be an effect of previous increased catecholamine turnover, which can induce mood effects in other brain regions. This may be similar to the different effects of amphetamine application. In this study, we further investigated the proposed dopaminergic effects of SD by comparing the eye-blink rates before and after SD in depressed patients and controls. We additionally used bromocriptine as a dopaminergic challenge, because we expected smaller effects to become evident only under a challenge condition, and the bromocriptine challenge could further validate the hypothesis that eye-blink is regulated by the dopamine system. We proposed the following hypotheses: SD increases blinking. SDinduced blinking is greater in depressed patients than in controls and correlates positively with the SD response. Bromocriptine increases blinking. Differences between patients and controls are more pronounced after bromocriptine challenge.

\section{METHODS}

The study was approved by the Ethics Commitee of the University of Erlangen. Twelve male drug-naive patients with major depression according to DSM-III-R criteria and 12 male healthly controls without a past or actual history of psychiatric disorders (DSM-III-R) were compared. We investigated males, because sex differences of the dopamine system cannot be excluded, and a much larger sample size would have been necessary to control both for sex and female cycle without adding further information to the SD-related questions. Both patients and controls were diagnosed by structured clinical interview for DSM-III-R (Spitzer et al. 1987), and psychopathology was assessed by the European AMDP-system (1979).
The following inclusion criteria had to be fulfilled: age between 25 and 50 years; no evidence of physical illness in physical examination, laboratory parameters, or electroencephalography, no other axis I disorder; no medication; no agitated form of depression (defined as moderate or severe psychomotor agitation or flight of ideas in the AMDP-system); and no seasonal affective disorder (defined according to the DSM-III-R criteria).

The study protocol did not differ between patients and controls.

Day 1 between 8:00 A.M. and 10:00 A.M.: First assessment of blink rate--application of $2.5 \mathrm{mg}$ bromocriptine (oral, approximately 15 to 30 minutes after food)second assessment of blink rate 1 hour after the bromocriptine application.

Day 1 to day 2: Total sleep deprivation (SD).

Day 2 between 8:00 A.M. and 10:00 A.M.: Same procedure as on day 1 .

All investigations were performed under the same lighting conditions and in the same photoperiod during the winter months December, January, or February. Sleep deprivation was monitored by the nursing staff. Additionally, a portable EEG-system (Sleep IT system, Fa. Jaeger, Wuerzburg, two-channel system with standard electrode placement) was applied during SD to ensure that none of the participants in the study had micro-sleep episodes. During SD, sitting in upright position and walking was allowed. An actometer was used to control for physical activity with both groups not being different during SD. The portable EEG-system is sensitive to detect sleep episodes, but it is not usable for polysomnography. The probands, therefore, were not screened on polysomnography for sleep disorders before the study. The 60 -minute interval between the bromocriptine application and the start of video observation was chosen, because under these circumstances the maximum plasma levels of bromocriptine were reached during blink rate assessment, which started 10 minutes after the beginning of video observation (maximum plasma level $72 \pm 24$ minutes after oral application, Schran et al. 1980; Drewe et al. 1988). After acute oral application of $2.5 \mathrm{mg}$ bromocriptine, plasma prolactin decreased after 60 minutes indicating a central effect at this timepoint (Manelli et al. 1984). In green monkeys, oral bromocriptine increased blink rate after 60 minutes but not after 45 minutes (Karson 1983).

The blink rate was measured by observation from video. After 10 minutes of accommodation to the recording environment, the blinks were measured during four conditions each lasting 3 minutes: listening to the investigator, silence, reading a text, calculating. The blinks during the 3-minute periods were counted by two independent raters who were blind for diagnosis and sleep condition. It was planned to use the mean of the two ratings for statistical evaluation, but the two 
raters never differed in their ratings. Both patients and probands were blind for the purpose of the study, and they didn't know that blink rates were measured. We used video observation, because this method seemed to be the best way to keep patients and raters blind to the purpose of the study, diagnosis, or sleep condition. Previous studies mostly used electrophysiologic measurements or direct observation. Direct observations correlate highly with electrophysiological measures (Karson 1983), and the blink rate is determined reliably between observers and over time (Karson et al. 1990). In a pilot study, we compared electrophysiologic measures, direct observation, and video observation in 10 probands. The correlation for the blink rates measured electrographically, and the ratings by video observation was 0.90 . The correlation for the blink rates measured by direct observation and those measured by video observation was 0.95 . Because of the high correlations, the different methods of blink counting were regarded as interchangeable.

Ratings of depression were performed at 8:00 A.M. (Clinical Global Impression Scale [CGI] and Hamilton Depression Rating Scale, 21-item version [HDRS]). The questions 4, 5, 6, 16, 18 were omitted, because they cannot be applied in SD studies. According to previous studies, those patients were defined to be SD responders who showed a $40 \%$ decrease on the HDRS and who were at least much improved on the CGI-scale (Ebert et al. 1991, 1993, 1994a,b; Wu et al. 1992). Raters were blind for eye-blink rates.

\section{Statistics}

For statistical comparison, a repeated measures ANOVA with group (patients vs. controls) by condition (sleep vs. SD, before vs. after bromocriptine) interactions was performed. Post-hoc, pre-SD and post-SD values and prebromocriptine and postbromocriptine values were compared with Wilcoxon tests. Patients and controls were compared post hoc with U-tests for pre$\mathrm{SD}$ and post-SD values and for the change scores (after $\mathrm{SD}$ minus before $\mathrm{SD}$, after SD plus bromocriptine minus before SD plus bromocriptine). Four separate ANOVAs were performed for the four conditions of blink-rate assessment. Nonparametric tests were used post hoc, because blink rate is not normally distributed. ANOVA is reasonably robust with data that are nonnormal in distribution. Spearman correlations were calculated for age and blinking, age and change score of blinking, SD response and blink rate response for all four conditions (listening, silence, reading, calculating) of blinking. Intercorrelations of the four blink rates were tested with Spearman correlations. With this statistical approach, multiple testing increases the possibility of type I error. Significant results have to be seen as preliminary, and the study should be interpreted as a hypothesis-generating study, not as a hypothesis-confirming study.

\section{RESULTS}

All patients and all controls were male. The patients were significantly older than the controls $(40.4 \pm 12.3$ years, range 26 to 50 years versus $32.3 \pm 8.7$ years, range 25 to 40 years). Before $S D$, the patients had a mean HDRS score of $28.8 \pm 1.81$; after SD, the mean HDRS decreased to $16.0 \pm 3.2$ (questions $4,5,6,16,18$ omitted). Duration of depression was 2 to 8 weeks. None of the patients had a bipolar course. According to the aforementioned criteria, eight patients were SD responders $(39 \pm 11.5$ years, HDRS $28.0 \pm 1.5)$, four patients were SD nonresponders ( $42.2 \pm 10.3$ years, HDRS $30.4 \pm 1.8)$. Responders and nonresponders were not significantly different in age or HDRS scores (U-test, $p>.1$ ). Two patients (28 and 40 years, HDRS 34 and 29) showed objective psychomotor retardation according to the AMDP-system (1979). Blink rates and change scores of blink rate during listening, reading, calculating, and silence were positively correlated $(p<.05$, Spearman, Table 1). As described earlier (Karson et al. 1981c) blink rate was lowest during reading and highest during calculating (requiring speech and memorizing). In none of the four blink conditions were significant correlations of blinking and age or change scores of blinking and age present ( $p>.1$, Spearman). Both in the depressed group and in the control group, there was a bimodal distribution of low blinkers (blink rate $<20$ /minute during silence) and high blinkers (blink rate $>40 /$ minute during silence). In both groups, eight participants were low blinkers and four were high blinkers.

ANOVA showed significant within-subjects effects of condition and significant group by condition interactions for silence, listening, reading, but not for calculating (Table 2). The blink rates of patients and controls and the results of post hoc contrasts are shown in Table 3 . We found the following main results: basal blink rates before SD were not different (all blink conditions). After $\mathrm{SD}$, the depressed patients, but not the controls, had significantly increased blink rates compared to the pre-

Table 1. Spearman Correlation Coefficients of the Four Blink-Rate Conditions at Baseline $(n=24)$

\begin{tabular}{lcccc}
\hline & Silence & Listening & Calculating & Reading \\
\hline Silence & & $0.6653^{b}$ & $0.5499^{b}$ & $0.4837^{a}$ \\
Listening & $0.6653^{b}$ & & $0.4587^{a}$ & $0.4385^{a}$ \\
Calculating & $0.5499^{b}$ & $0.4587^{a}$ & & $0.4374^{a}$ \\
Reading & $0.4837^{a}$ & $0.4385^{a}$ & $0.4374^{a}$ & \\
\hline
\end{tabular}

\footnotetext{
${ }^{a} p<.05$.
}

${ }^{b} p<.005$. 
Table 2. Results of the Four Repeated Measures ANOVAs with Effects of Condition (Sleep/Sleep Deprivation, Before Bromocriptine/After Bromocriptine) and Group (Depression/Controls) by Condition Interactions

\begin{tabular}{llll}
\hline & \multicolumn{3}{c}{ ANOVA } \\
\cline { 2 - 4 } & \multicolumn{2}{c}{ Condition } & Group by Condition \\
\hline Silence & $d f=3, F=4.45, \quad p<0.007$ & $d f=3 \quad F=2.88, \quad p<0.45$ \\
Listening & $d f=3, F=2.85, \quad p<0.048$ & $d f=3, \quad F=4.67, p<0.006$ \\
Reading & $d f=3, F=2.85, p<0.048$ & $d f=3, \quad F=2.92, p<0.044$ \\
Calculating & $d f=3, F=2.61, p<0.063$ & $d f=3, \quad F=2.61, p<0.063$ \\
\hline
\end{tabular}

SD values (all blink conditions). The change scores (post-SD minus pre-SD) were significantly higher in patients than in controls both without bromocriptine (silence) and with bromocriptine (all blink conditions except silence). Blink rate did not increase after bromocriptine (all blink conditions).

As seen in Table 4, the effects of SD on blinking were greater in SD responders than in nonresponders. The decrease in HDRS score after SD was significantly correlated to the increase in blinking (silence $r=0.6734$, $p<.05$, Spearman; listening $r=0.6844, p<.05$, Spearman; reading $r=5.797$, NS; calculating $r=0.7543, p<$ .05 , Spearman).
The two retarded patients had the lowest basal blink rates (silence: $5 /$ minute and $10 /$ minute, statistic comparisons were not performed because of the small number).

\section{DISCUSSION}

The blink rates of 12 depressed patients and 12 controls were compared before and after SD and before and after a dopaminergic challenge with $2.5 \mathrm{mg}$ bromocriptine. The depressed patients had a significantly higher increase in blinking after SD both with and without the dopaminergic challenge, and the increase in blinking

Table 3. Eye-Blink Rates of 12 Male Patients with Major Depression and 12 Male Healthy Controls Before and After Sleep Deprivation and Before and 1 Hour After $2.5 \mathrm{mg}$ Bromocriptine

\begin{tabular}{llc}
\hline & \multicolumn{2}{c}{ Blink Rate (Blinks per Minute, Mean \pm SD) } \\
\cline { 2 - 3 } \multicolumn{1}{c}{ Condition } & Patients $(\boldsymbol{n}=\mathbf{1 2})$ & Controls $(\boldsymbol{n}=\mathbf{1 2})$ \\
\hline 1. Silence & & \\
pre-SD & $23.8 \pm 22.4$ & $18.4 \pm 13.2$ \\
pre-SD + bromocriptine & $20.5 \pm 21.4$ & $19.5 \pm 18.3$ \\
post-SD & $38.3 \pm 34.1^{a, c}$ & $20.5 \pm 18.0$ \\
post-SD + bromocriptine & $36.6 \pm 37.4^{b}$ & $15.6 \pm 11.2$ \\
2. Listening & & \\
pre-SD & $20.1 \pm 16.1$ & $19.6 \pm 10.2$ \\
pre-SD + bromocriptine & $18.4 \pm 13.5$ & $26.6 \pm 16.7$ \\
post-SD & $30.0 \pm 26.1^{a}$ & $24.3 \pm 16.9$ \\
post-SD + bromocriptine & $32.7 \pm 25.6^{b, c}$ & $18.5 \pm 12.3$ \\
3. Reading & & \\
pre-SD & $2.3 \pm 1.1$ & $5.1 \pm 4.6$ \\
pre-SD + bromocriptine & $2.4 \pm 1.6$ & $4.9 \pm 4.1$ \\
post-SD & $6.4 \pm 5.4^{a}$ & $7.0 \pm 5.4$ \\
post-SD + bromocriptine & $7.7 \pm 9.5^{b, c}$ & $4.5 \pm 3.7$ \\
4. Calculating & & \\
pre-SD & $30.5 \pm 16.2$ & $27.4 \pm 21.9$ \\
pre-SD + bromocriptine & $29.7 \pm 15.9$ & $32.1 \pm 22.7$ \\
post-SD & $39.9 \pm 22.6^{a}$ & $31.3 \pm 22.7$ \\
post-SD + bromocriptine & $41.1 \pm 20.1^{b, c}$ & $26.1 \pm 19.6$ \\
\hline
\end{tabular}

${ }^{a}$ Wilcoxon test $p<.05$ : Within-group comparison before SD versus after SD

${ }^{b}$ Wilcoxon test $p<.05$ : Within-group comparison bromocriptine before SD versus bromocriptine after SD. ${ }^{\prime} \mathrm{U}$-test $p<.05$ : Between-group comparison change score post-SD minus pre-SD patients versus controls. No significant within-group comparisons in the control group. No significant effects of bromocriptine. 
Table 4. Eye-Blink Rates of Eight Sleep Deprivation Responders with Major Depression and Four Sleep Deprivation Nonresponders

\begin{tabular}{|c|c|c|}
\hline \multirow[b]{2}{*}{ Condition } & \multicolumn{2}{|c|}{ Blink Rate (Blinks per Minute, Mean \pm SD) } \\
\hline & Responders $(n=8)$ & Nonresponders $(n=4)$ \\
\hline $\begin{array}{l}\text { 1. Silence } \\
\text { pre-SD } \\
\text { post-SD }\end{array}$ & $\begin{array}{l}26.3 \pm 22.6 \\
43.6 \pm 38.6^{a . b}\end{array}$ & $\begin{array}{l}18.8 \pm 18.2 \\
27.7 \pm 24.0\end{array}$ \\
\hline $\begin{array}{l}\text { 2. Listening } \\
\text { pre-SD } \\
\text { post-SD }\end{array}$ & $\begin{array}{l}20.5 \pm 17.7 \\
32.9 \pm 29.8^{a, b}\end{array}$ & $\begin{array}{l}19.3 \pm 17.2 \\
24.2 \pm 16.9\end{array}$ \\
\hline $\begin{array}{l}\text { 3. Reading } \\
\text { pre-SD } \\
\text { post-SD }\end{array}$ & $\begin{array}{l}2.7 \pm 0.9 \\
6.9 \pm 5.9^{a}\end{array}$ & $\begin{array}{l}1.5 \pm 2.0 \\
5.4 \pm 5.1^{a}\end{array}$ \\
\hline $\begin{array}{l}\text { 4. Calculating } \\
\text { pre-SD } \\
\text { post-SD }\end{array}$ & $\begin{array}{l}32.8 \pm 16.8 \\
44.0 \pm 23.3^{a, b}\end{array}$ & $\begin{array}{l}25.9 \pm 20.9 \\
31.7 \pm 22.0\end{array}$ \\
\hline
\end{tabular}

was correlated to the decrease in HDRS-scores. This result is consistent with the hypothesis that antidepressant SD acts through enhanced dopamine release in depressed patients. We controlled for other factors possibly influencing blink rate, like medication, photoperiod, or light entrainment (Karson 1984, Stevens and Livermore 1978). Different age may have contributed to the results, although we did not find any correlation of age and blinking or age and change score of blinking. Previous studies only indicated correlations in younger patients (Karson et al. 1986), and it is assumed that age does not correlate with blink rate after puberty (Zametkin et al. 1979). Although the finding of increased blinking in responders after SD is consistent with the notion that SD may mediate its antidepressant effect by dopamine release, it is not conclusive. First, the design of the study runs the risk of a false syllogism: if increased dopamine increases eye-blinks and if SD in patients increases eye-blinks, we cannot conclude that increased eye-blinks after SD indicate increased dopamine. At that point, the dopamine hypothesis can only be discussed as one possible hypothetical interpretation. Second, Karson (1983) has shown that anticholinergic agents like atropine also increase blinking, and cholinergic substances like physiostigmine decrease blinking. Adrenergic agents or LSD do not have any effects. Therefore, at least two systems seem to be involved in blinking. It may be of interest that $\mathrm{SD}$ also has been proposed to develop its antidepressant effects by anticholinergic mechanisms (e.g., Wu et al. 1992). Such an interpretation would be compatible with our blink data, too. Third, we could not demonstrate a significant effect of the bromocriptine challenge after 1 hour. This bromocriptine challenge was meant to validate the dopamine hypothesis, but it did not. From studies with monkeys (Karson et al. 1983), other results could be expected. Possibly, the chosen bromocriptine dose was too low, or the route of application and differences in metabolism resulted in invididual differences of the time of onset of the bromocriptine effects. Indeed, two patients and two controls had a significant effect after 1 hour, and, for future research, a more flexible measurement of blink rate is recommended. Another explanation for the negative bromocriptine effects on blinking accounts for the receptor-binding profile of the substance: like apomorphine it has dopamine $\mathrm{D}_{2}$ and $\mathrm{D}_{3}$ receptor agonistic properties, but, different from the latter, bromocriptine has also some dopamine $D_{1}$ receptor antagonistic effect (Sokoloff et al. 1992). Possibly, $\mathrm{D}_{1}$ activation is necessary for activation of blinking in humans. For further research the design might be strengthened by the addition of appropriately timed prolactin levels as an independent measure of dopamine and by bromocriptine serum levels. Another complexity of the findings makes a simple dopaminergic interpretation of the data difficult. Blink rate also depends on the mental activity state or the activity of certain brain regions involved in blinking. We do not know whether patients and controls differed after SD in regard to these parameters. Although the four conditions of blink rate assessment were correlated to each other and the SD-induced change was nearly the same in all four conditions, the variance among these four conditions is higher than the magnitude of effect of SD. This means that variability of mental state may have influenced the results. Another result needs some comment. From the dopamine hypothesis 
of depression, we would have expected lower baseline blink rates in depression. However, the brain regions involved in blinking are not the same as those areas that have been postulated to be involved in depression. A general decrease in brain dopamine release or dopamine turnover is only shown for depressed patients with objective psychomotor retardation, but not for the whole group of major depression (Willner 1994). In our group, only two patients had visible signs of psychomotor retardation, and these two patients indeed had the lowest basal blink rate of all patients and probands. For further research, it is therefore recommended to compare psychopathologically well-defined groups with controls. For example, Depue et al. (1990) investigated distinct depressive subtypes, finding an increase in blinking in seasonal affective disorder. Although our data are not really comparable, they give at least some evidence that increased blinking is not an effect of depression itself, but an effect of the seasonal subtype of depression, because we excluded patients with seasonal affective disorder.

\section{CONCLUSIONS}

Basal eye-blink rate is not altered in nonretarded major depression compared to controls. Sleep deprivation increases blink rate in depression but not in controls, and the increase correlates to a positive sleep deprivation response. Bromocriptine does not increase blink rate 1 hour after application. The data are consistent with a hypothesis of enhanced dopamine release in antidepressant sleep deprivation, but they are not conclusive. Other transmitters like acetylcholine also may be involved. Further research is needed to establish the role of the dopamine system in the control of blinking.

\section{ACKNOWLEDGMENT}

This study was supported by grant DFG EB 144-2, Deutsche Forschungsgemeinschaft.

\section{REFERENCES}

Arbeitsgemeinschaft für Methodik und Dokumentation in der Psychiatrie (1979): Das AMDP-System. Springer, Berlin

Casey DE, Gerlach J, Christenson E (1980): Behavioral aspects of GABA-dopamine interrelationships in the monkey. Brain Res 5:269-273

Depue RA, Arbisi P, Krauss S, Iacono WG, Leon A, Muir R, Allen J (1990): Seasonal independence of low prolactin concentration and high spontaneous eye blink rates in unipolar and bipolarII seasonal affective disorder. Arch Gen Psychiatry 47:356-364

Doane MG (1994): Tear film and blink dynamics. In Albert M, Jakobiek R (eds) Principles and Practice of Ophthalmology-basic Sciences. Saunders, Philadelphia, PA pp 1049-1051

Drewe J, Mazer N, Abisch E, Krummen K, Keck M (1988): Differential effect of food on kinetics of bromocriptine in a modified release capsule and a conventional formulation. Eur J Clin Pharmacol 35:535-541

Ebert D, Feistel H, Barocka A (1991): Effects of sleep deprivation on the limbic system and the frontal lobes in affective disorders: A study with Tc99m HMPAO SPECT. Psychiatry Res: Neuroimaging 40:247-251

Ebert D, Kaschka WP, Stegbauer P, Schrell U (1993): Prolactin response to sulpiride in depression before and after sleep deprivation. Biol Psychiatry 35:880-885

Ebert D, Feistel H, Barocka A, Kaschka WP (1994a): Increased limbic blood flow and total sleep deprivation in major depression with melancholia. Psychiatry Res: Neuroimaging 55:101-109

Ebert D, Feistel H, Barocka A, Kaschka WP, Pirner A (1994b): SPECT assessment of cerebral dopamine $D_{2}$ receptor blockade in depression before and after sleep deprivation. Biol Psychiatry 35:880-885

Ebert D, Kaschka WP (1995): Humorale Aspekte des Schlafentzuges. Fortschritte der Neurologie and Psychiatrie (in press)

Ebert D, Ebmeier K (1995): The role of the cingulate gyrus in depression-From functional neuroanatomy to neurochemistry. Biol Psychiatry (in press)

Fibiger HC (1995): Neurobiology of depression: Focus on dopamine. In Gessa G, Fratta W, Pani L, Serra G (eds), Depression and mania: From Neurobiology to Treatment. Raven Press, New York, pp 1-17

Francis J, Hernandez LL, Powell DA (1981): Lateral hypothalamic lesions: Effects on Pavlovian cardiac and eyeblink conditioning in the rabbit. Brain Res Bull 6:155-163

Gessa G, Pani L, Serra G, Fratta W (1995): Animal models of mania. In Gessa G, Fratta W, Pani L, Serra G (eds), Depression and mania: From neurobiology to treatment. Raven Press, New York, pp 43-66

Hall A (1945): The origin and purposes of blinking. Br J Ophthalmol 445-467

Kao KT, Powell DA (1988): Lesions of the substantia nigra retard Pavlovian eye-blink but not heart rate conditioning in the rabbit. Behav Neurosci 102:515-525

Karson CN, Staub RA, Kleinman JE, Wyatt RJ (1981a): Drug effect on blink rates in rhesus monkeys: Preliminary results. Biol Psychiatry 16:249-254

Karson CN, Freed WJ, Kleinman JE, Bigelow LB, Wyatt RJ (1981b): Neuroleptics decrease blinking in schizophrenic patients. Biol Psychiatry 16:679-682

Karson CN, Berman KF, Donnelly EF, Mendelson WB, Kleinman JE, Wyatt RJ (1981c): Speaking, thinking, and blinking. Psychiatry Res 5:243-246

Karson CN (1983): Spontaneous eye-blink rates and dopaminergic systems. Brain 106:643-653 
Karson CN, Berman KF, Kleinman JE, Karoum F (1984): Seasonal variation in human central dopamine activity. Psychiatry Res 11:111-117

Karson CN, Goldberg TE, Leleszi JP (1986): Increased blink rate in adolescent patients with psychosis. Psychiatry Res 17:195-198

Karson CN, Dykman RA, Paige SR (1990): Blink rates in schizophrenia. Schizophr Bull 16:345-354

Lawrence MD, Redmond E (1991): MTPT lesions and dopaminergic drugs alter eye blink rate in African green monkeys. Pharmacol Biochem Behav 38:869-874

Mackintosh JH, Kumar R, Kitamura T (1983): Blink rate in psychiatric illness. Br J Psychiatry 143:55-57

Mannelli M, Delitalia G, DeFeo LM, Maggi M, Cuomo S, Piazzini M, Guazelli R, Serio M (1984): Effects of different dopaminergic antagonists on bromocriptine-induced inhibition of norepinephrine release. J Clin Endocrinol Metab 59:74-78

McCann UD, Penetar DM, Shaham Y, Thorne TR, Gillin JC, Sing HC, Thomas ML, Belenky G (1992): Sleep deprivation and impaired cognition. Biol Psychiatry 31:10821097

McCann UD, Penetar DM, Shaham Y, Thorne TR, Sing HC, Thomas ML, Gillin JC, Belenky G (1993): Effects of catecholamine depletion on alertness and mood in rested and sleep-deprived volunteers. Neuropsychopharmacology 8:345-356

McCann UD, Thorne TR, Hall M, Popp K, Avery W, Sing HC, Thomas ML, Belenky G (1995): The effects of L-Dihydroxyphenylalanine on alertness and mood in alphamethyl-paratyrosine-treated healthy humans. Neuropsychopharmacology 13:41-52

Ostow M, Ostow M (1945): The frequency of blinking in mental illness. J Nerv Ment Dis 102:294-301

Pearlson GD, Schlaepfer TE (1995): Brain imaging in mood disorders. In Bloom FE, Kupfer DJ (eds), Psychopharmacology. Raven Press, New York, pp 1019-1028
Records RE (1993): Eyebrows and eyelids. In Doane MG (ed), Doane's Foundations of Clinical Ophthalmology, vol 2. Lippincott, Philadelphia, PA, 1:17-22

Schran HF, Bhuta SI, Schwarz HJ, Thorner MO (1980): The pharmacokinetics of bromocriptine in man. Adv Biochem Psychopharmacol 23:125-139

Simons E, Smith PG (1994): Sensory and autonomic innervation of the rat eyelid. J Chem Neuroanat 7:35-47

Sokoloff P, Andrieux M, Besancon R, Pilon C, Martres M, Giros B, Schwartz JC (1992): Pharmacology of human dopamine $D_{3}$ receptor expressed in mammalian cell line: Comparison with $\mathrm{D}_{2}$ receptor. Eur J Pharmacol 225:331-337

Sokolski KN, Reist C, Chen C, DeMet EM (1995): Antidepressant responses and changes in visual adaptation after sleep deprivation. Psychiatry Res 57:197-207

Spitzer RL, Williams JBW, Mirian G (1987): Structured Clinical Interview for DSM-III-R. New York, New York State Psychiatric Institute

Stevens JR, Livermore A (1978): Eye blinking and rapid eye movement: Pulsed photic stimulation of the brain. Exp Neurol 60:541-556

Stevens JR (1978): Eye blink and schizophrenia: Psychosis or tardive dyskinesia? Am J Psychiatry 135:223

Willner P (1994): Dopaminergic mechanisms in depression and mania. In Bloom FE, Kupfer DJ (eds), Psychopharmacology. New York, Raven Press, pp 921-932

Wu JC, Gillin JC, Buchsbaum MS, Hershey T, Johnson JC, Bunney WE (1992): Effects of sleep deprivation on brain metabolism of depressed patients. Am J Psychiatry 149:538-543

Wu JC, Gillin JC, Buchsbaum MS, Cadwell S, Lottenberg S, Bunney WE (1994): PET studies of sleep deprivation in unipolar depression. Neuropsychopharmacology 10 (3s): $876 S$

Zametkin AJ, Stevens JR, Pittman R (1979): Ontogenity of spontaneous blinking and habituation of the blink reflex. Ann Neurol 5:453 